\title{
Precipitation of disordered dolomite catalyzed by dissolved silica
}

\author{
YIHANG FANG ${ }^{1}$ HUIFANG XU ${ }^{2}$
}

${ }^{1} 1215$ West Dayton St, Madison, WI 53706, fang9@wisc.edu

${ }^{2} 1215$ West Dayton St, Madison, WI 53706,

hfxu@geology.wisc.edu

The discrepancy of dolomite prevalence between great abundance in the Proterozoic and Lower Paleozoic and scarcity in then Cenozoic suggests a poorly understood, but dramatic shift in the geochemical system that inhibited dolomite. Previous works on microbial-mediated dolomite demonstrated that microbial activities can promote disordered dolomite precipitation through catalytic roles of polysaccharides. However, the microbial-mediated model cannot explain some of the Precambrian dolomite without no evidence of microbial origin. Here, we present an abiotic mechanism with dissolved silica catalyzed dolomite precipitation that provide new insight onto this long-lasting "dolomite problem". In this study, we demonstrate that the presence of 1-2 $\mathrm{mM}$ of aqueous $\mathrm{Si}(\mathrm{OH})_{4}$ in high $\mathrm{Mg}$ :Ca ratio solutions at room temperature will promote disordered dolomite (with up to $48.7 \mathrm{~mol} \% \mathrm{MgCO}_{3}$ ) precipitation and inhibit aragonite precipitation. Dissolved silica increase in solution also promotes $\mathrm{Mg}$ incorporation into the $\mathrm{Ca}-\mathrm{Mg}$ carbonates. Low dielectric constant additives interrupted the surface of magnesium hydration shell and decrease the dehydration energy. These additives, therefore, promote both homogeneous and heterogeneous nucleation and subsequently catalyzed dolomite growth. Established room temperature dolomite synthesis experiments all require the presence of dissolved molecules with low dipole moments such as hydrogen sulfide, dioxane, polysaccharide and exopolymeric substances (EPS). The molecules with low dipole moment adsorbed on the dolomite surface can lower the dehydration energy of a surface $\mathrm{Mg}^{2+}$-water complex and promote dolomite nucleation and growth. In this study, we demonstrate that the presence of $1-2 \mathrm{mM}$ aqueous $\mathrm{Si}(\mathrm{OH})_{4}$ in high $\mathrm{Mg}: \mathrm{Ca}$ ratio solutions at room temperature will promote disordered dolomite precipitation and inhibit aragonite precipitation. This study provides a new model for abiotic sedimentary dolomite formation which is likely to be responsible for the significant amount of primary dolomite in the Earth history. 